A. Moghayadniya, E. Razavi

\title{
REACTIVE POWER CONTROL IN MICRO-GRID NETWORKS USING ADAPTIVE CONTROL
}

Purpose. Despite their economic and environmental benefits, distributed products in power systems have caused problems in power systems. One of the most important issues in this regard is voltage fluctuations and frequencies in Micro-grids, which depends on several factors, such as variable consumption load and errors in power systems. One of the main challenges associated with the use of Micro-grids is power management among distributed generation sources. Power management plays a pivotal role in numerous Micro-grids and may ensure the stable and improved performance of Micro-grids in the permanent status of the system. The present study aimed to examine the power control in Micro-grids by proposing an adaptive control method along with the PID controller for power management and coordination in Micro-grids. This coordination system operates between production sources and controlling the voltage and frequency levels against the possible disturbances occurring anywhere in the system loop. The results of the simulation of the proposed algorithm in MATLAB software environment exhibited a high success rate (i.e., proper response to the fluctuations in the Micro-grid) and extremely low error rate (i.e., proper reactive power in the grid). References 17, tables 3, figures 12.

Key words: Micro-grid, control parameters, online parameter setting, proportional-integral-derivative controller (PID), adaptive control.

Цель. Несмотря на их экономические и экологические преимущества, распределенные продукты в энергосистемах приводят к возникновению проблем в последних. Одним из наиболее важных вопросов в этой связи являются колебания напряэсения и частоты в микросетях, которые зависят от нескольких факторов, таких как переменная нагрузка потребления и ошибки в энергосистемах. Одной из основных проблем, связанных с использованием микросетей, является энергоменеджмент источников распределенной генерации. Энергоменедэмент играет ключевую роль во многих микросетях и может обеспечить стабильную и улучиенную работу микросетей при постоянном состоянии системы. Настоящее исследование направлено на исследование энергоменедэсмента в микросетях путем предложения адаптивного метода управления вместе с ПИД-контроллером для энергоменеджмента и координации в микросетях. Эта система координации функционирует между источниками производимой энергии и контролирует уровни напряжения и частоты в отнощении возможных помех, возникающих в любом месте контура системы. Результаты моделирования предложсеного алгоритма в программной среде MATLAB показали высокую степень успеха (то есть правильную реакцию на колебания в микросети) и чрезвычайно низкую частоту ошибок (то есть надлежсащую реактивную мощность в сети). Библ. 17, табл. 3, рис. 12.

Ключевые слова: микросеть, параметры управления, онлайн настройка параметров, пропорционально-интегральнодифференцирующий (ПИД) контроллер, адаптивное управление.

Introduction. The structure of the power industry consists of producers, transmission lines and electrical equipment; the operators of this industry are still monitoring the state of the system with delays, which is about $10 \mathrm{sec}$ behind the actual time.

The above grid should use a wide range of sensors, communications and control techniques to improve the performance of production, transmission and distribution systems of electric power, and move towards a more reliable and an optimized power system, cost effective and eco-friendly system by providing a ground for distributed production and using renewable sources [1]. A Micro-grid typically consists of a set of distributed sources, a power storage system, and loads which may be used via connecting to the global power grid or via the island function (independent). Distributed generation refers to cases where electricity is produced at the same place of consumption or near the place of consumption [2].

From the perspective of consumers, Micro-grid is capable of providing increased reliability, improved power quality and reduced consumption costs. From the point of view of the power companies, the use of Microgrid has the potential to reduce consumption and thus reduce the facilities required for the development of transmission lines, and in addition to eliminating peak consumption points, it reduces grid losses.

The topic of frequency and voltage stability is one of the significant factors that should be taken into account in the planning and exploitation of Micro-grid in order to avoid the collapse of voltage and off in system. Regarding the fact that there are not an infinite number of Micro-grid buses, and most power supply sources have power interfaces, the main concern in controlling Micro-grid is the control of electronic power converters [4]. In connected state, the Micro-grid does not have many problems with voltage and frequency stability. This is due to the fact that it is connected to system with far higher inertia than itself, and if it has a shortage of production, it will be distributed from the larger system [5]. But in the island state, the worst problem deals with the instability of the voltage and frequency of the Micro-grid, and in many cases, it deals with the voltage and frequency drop. The overall Micro-grid inertia is low, and as a result of sudden changes in loads or faults, if there is no effective protection and control system, Micro-grid will quickly undergo instability and collapse.

Different structures have been developed to control Micro-grid in recent years. But in 2012, a relatively good initial structure for standardization was presented by Prof. Guererro, in which a PID Controller (hierarchical control) inspired from traditional and old power control system, which included: local control (primary), supplemental control (secondary) and Micro-grid power control (third) [6]. Prof. Beaverani has improved this hierarchical

(C) A. Moghayadniya, E. Razavi 
structure by modifying the three levels and adding a new loop to the structure. This new loop is Emergency Control of Micro-grid [7]. In Micro-grid, both the frequency and voltage parameters are simultaneously dependent on both the actual power and reactive power parameters. Even to improve this, other loops such as Loop Impedance have been established [8].

In a PID Controller, the loop of local control (primary) prevents the permanent drop but does not necessarily return it to the nominal values. The secondary control loop includes two voltage control and frequency control units, and consists of two loops with two regular PID controllers. The Micro-grid power control loop (third), which is the frequency synchronization, allows the loop to only connect the Micro-grid to the main grid when the phase difference of both systems is less than (low), so that the micro-grid is interrupted by transient disturbances. The synchronization operation is performed by the PID controllers [9].

At the island state, the third control loop can determine the amount of power generated by each distributed source, and in the connected state, it can take the amount of power imported or exported from the grid to the main grid. At the island state, the nominal values of the grid (ex. $220 \mathrm{~V}$ and $50 \mathrm{~Hz}$ ), and in connection state, the instant values of the voltage and frequency of the main grid will be the reference values. Among the controversial topics, we may point to the presence of virtual impedance and how to set these control factors. The reason for using a comparative controller is the simplicity of control in terms of performance as well as implementation [10].

Materials and methods. Micro-grid is part of a power system that includes distributed generation sources that operate as a load or power source and must be operational after being disconnected from the main grid.

The Micro-grid is connected to the distribution network in normal mode. If a fault or short circuit occurs in the distribution system, the fault detection system commands breaker and that the Micro-grid goes to autonomous or islanding mode. We have the highest number of frequency instability and voltage problems in islanding mode, and in most cases, we observe voltage and frequency drops. The overall Micro-grid inertia is low; therefore, sudden changes in load or faults in absence of an effective protection and control system, the Micro-grid experiences instant instability and collapse. In result, we need a controller that can stabilize the system.

Controlling distributed sources in Micro-grids bears high importance in optimizing and increasing the reliability and stability of power network. The PID controller is one of the most commonly used feedback controllers that has been used in a wide range of controlling processes such as DC motor speed control, pressure control, and temperature control, etc. The PID controller computes the «error» value between the process output and the desired input value. The goal of controller is to minimize error via adjusting process control inputs.

In fact, the PID controller is used to control the frequency and stability of the system and thus the power control. An example of controllers that are widely used in controlling industrial processes is called a Proportional-
Integral-Derivative controller or PID. Figure 1 shows block diagram of Unity Feedback System with controller.

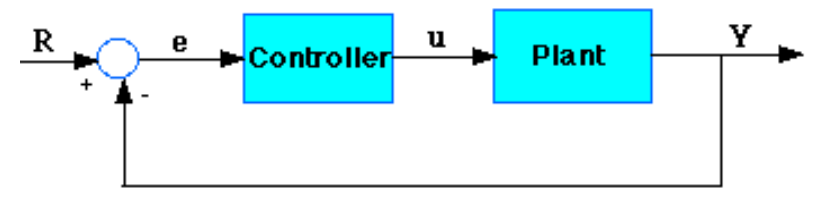

Fig. 1. Unity Feedback System

The transfer function of the PID controller appears as follows

$$
K_{P}+\frac{K_{I}}{s}+K_{D} s=\frac{K_{D} s^{2}+K_{P} s+K_{I}}{s},
$$

where $K_{P}$ - proportional gain, $K_{I}$ - integral gain, $K_{D}-$ derivative gain.

First, it is necessary to look at how the PID controller works in a closed-loop system using the schematic shown above. The variable (e) represents the tracking error, the difference between the desired input value (R) and the actual output (Y). This error signal (e) is sent to the PID controller, which computes both the derivative and the integral of this error signal. The signal (u), just past the controller, is now equal to the proportional gain $\left(K_{P}\right)$ times the magnitude of the error plus the integral gain $\left(K_{I}\right)$ times the integral of the error plus the derivative gain $\left(K_{D}\right)$ times the derivative of the error

$$
U=K_{P} e+K_{I} \int e \mathrm{~d} t+K_{D} \frac{\mathrm{d} e}{\mathrm{~d} t} .
$$

The signal $(\mathrm{u})$ is sent to the plant. The new output (Y) returns again to the sensor to find the new error signal (e). The proportional controller $\left(K_{P}\right)$ affects the on reduction of the rise time and the integral controller $\left(K_{I}\right)$ affects the elimination of the steady-state error. The derivative control $\left(K_{D}\right)$ affects the increase the stability of the system, reduce the overshoot, and improve the transient response. The effects of each of the Controllers $K_{P}, K_{D}$, and $K_{I}$ on a closed-loop system are summarized in the table below. Table 1 shows the effect of change in the coefficient of PID Controllers on rise time and steady state error in closed-loop system.

Table 1

Effect of PID controllers on a closed-loop system

\begin{tabular}{|c|c|c|c|c|}
\hline $\begin{array}{c}\mathrm{CL} \\
\text { response }\end{array}$ & Rise time & Overshoot & $\begin{array}{c}\text { Settling } \\
\text { time }\end{array}$ & S-S error \\
\hline$K_{P}$ & Decrease & Increase & $\begin{array}{c}\text { Small } \\
\text { change }\end{array}$ & Decrease \\
\hline$K_{I}$ & Decrease & Increase & Increase & Eliminate \\
\hline$K_{D}$ & $\begin{array}{c}\text { Small } \\
\text { change }\end{array}$ & Decrease & Decrease & $\begin{array}{c}\text { Small } \\
\text { change }\end{array}$ \\
\hline
\end{tabular}

In the Table $1 \mathrm{CL}$ is closed-loop system, overshoot is the occurrence of a signal or function exceeding its target, rise time is the time taken by a signal to change from a specified low value to a specified high value, settling time includes a propagation delay, plus the time required for the output to slew to the vicinity of the final value, recover from the overload condition associated with slew, and finally settle to within the specified error, 
S-S error is: steady state error. Steady-state error is defined as the difference between the input (command) and the output of a system in the limit as time goes to infinity (i.e. when the response has reached steady state).

In this section, an adaptive control is proposed in order to determine the parameters of the PID controller to deal with complex and uncertain conditions, which is due to reduced computations.

It is supposed that the PID controlling method determines the optimal optimization parameters based on adaptive control. This method applies an adaptive control method to find the optimal parameters. Therefore, the quality of detecting the range of optimal domain extracted for algorithm operation. The order of the effect of the suggested method is in extracting the best range of values; so that, it provides the closest PID controller values.

Adaptive control. In control of power systems, the dynamics of the system may be fully apparent at the start of operation, but its parameters face unpredictable changes through the control process. Therefore, the initially designed controller, which was initially appropriate, may not be able to control the changing system without the redesign of the controller. In general, the main purpose of the adaptive control is to consistently maintain the system's operation against parametric uncertainty or their uncertain changes. Regarding that such a parametric uncertainty and/or their variation may occur in many practical problems, adaptive control is useful in a number of industrial situations.

In existing adaptive methods in nonlinear systems, it is generally required to make the planetary dynamics linearly parametric, i.e. parametric uncertainty is functionally expressed as a line of an uncertain set of parameter. Linear parameterization and in result, adaptive control cannot be reached in some cases, but resistant control (or adaptive control with semi resistant sentences) may be possible.

An adaptive controller differs with a regular controller from the point that the controller parameters are changeable in it and that there is a mechanism based on system signals used for timely adjustment of such parameters. In the design of non-adaptive controllers, the structure (such as the polarity determination) is firstly determined, and then the controller parameters are computed based on the system parameters. In the adaptive control, the essential difference is that the system parameters are uncertain; so, the controller parameters should be obtained by an adaptive law. Consequently, adaptive control design is more complicated because of the additional requirements of the selecting adaptation law and proving system stability against adaptation.

The basis of adaptive control is the parameter estimation that is a branch of system identification. Common estimation methods include recursive least squares and descending gradients.

In fact, adaptive control systems are often used to control time variable parameters. The design of a comparative controller usually involves the following three steps:

- selecting a control law that includes variable parameters;
- selecting an adaption law to set these parameters;

- analyzing the properties of the convergence of the resulting control systems.

Many distributed generation sources, such as fuel cells, photovoltaic cells and microturbines, are connected through a grid voltage source inverter. Therefore, in order to control power, distributed generation sources are connected as a DC voltage source and through the inverter to the grid (Fig. 2).

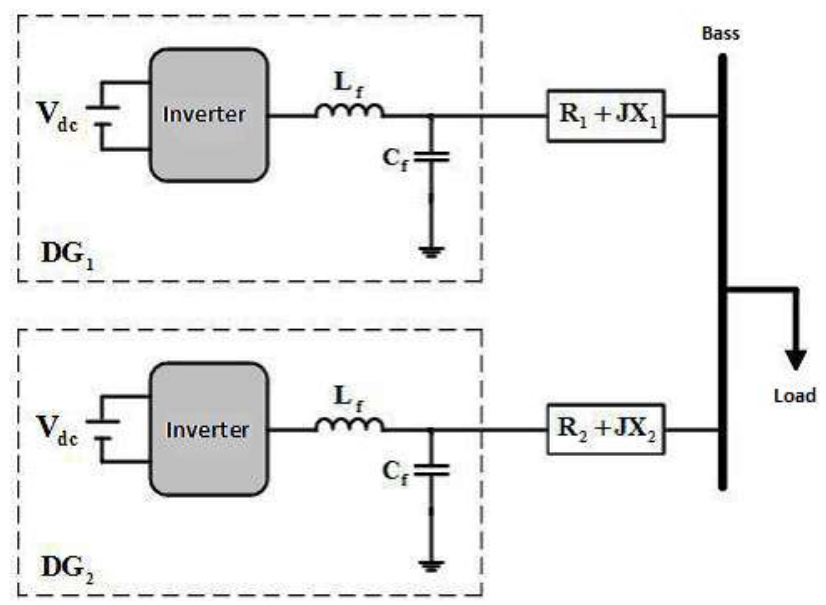

Fig. 2. The structure of the network studied

Tiny network structure studied. Distribution sources can be an island for some reason, such as error or planning, to maintain their goals. In this state of operation, the distributed generation sources have no connection to the main grid. Therefore, the power control strategy of this state of operation should meet the following objectives:

- adjusting frequency;

- maintaining and adjusting voltage;

- managing the distribution of active and reactive powers between distributed island sources;

- performing proper distribution of power between sources when changing loads.

Figure 3 shows the controller in island state. The controller constitutes of three main components of power control, voltage control and current control, which are described below.

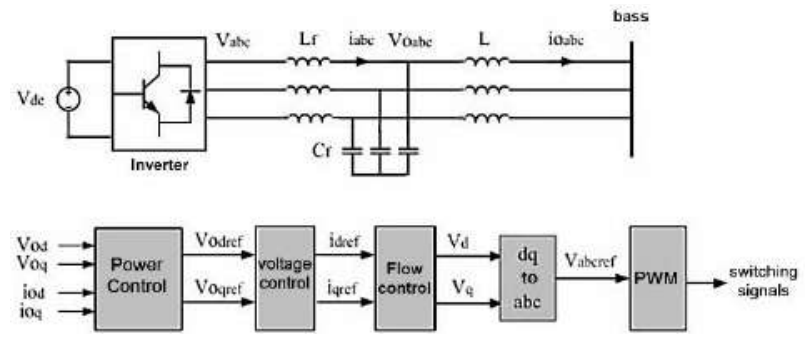

Fig. 3. Controller in the island fashion

Reactive power control. In the control of reactive power, the Droop method has been used to calculate the active and reactive power of the inverter output using the measured values of the current and the inverter output voltage. It also uses a low pass filter whose off frequency is $10 \%$ of the nominal frequency of the system, to eliminate oscillations and obtain essential output power content. 
Equations (3) and (4) indicate the power computation method.

$$
\begin{aligned}
& P=\frac{3}{2} \cdot \frac{\omega_{C}}{S+\omega_{C}}\left(V_{o d} I_{o d}+V_{o q} I_{o q}\right) ; \\
& Q=\frac{3}{2} \cdot \frac{\omega_{C}}{S+\omega_{C}}\left(V_{o q} I_{o d}+V_{o d} I_{o q}\right) .
\end{aligned}
$$

The Drop features are used up to the provision of a drop in the range and frequency of the output voltage, as follows

$$
\begin{gathered}
\omega=\omega_{n}-m P ; \\
V=V_{n}-n Q .
\end{gathered}
$$

Finally, the controller is designed in a way to allocate the reference voltage, obtained by the Droop method, to the $d$-axis and set the reference $q$ to zero. These reference values are voltage control inputs (Fig.4-6).

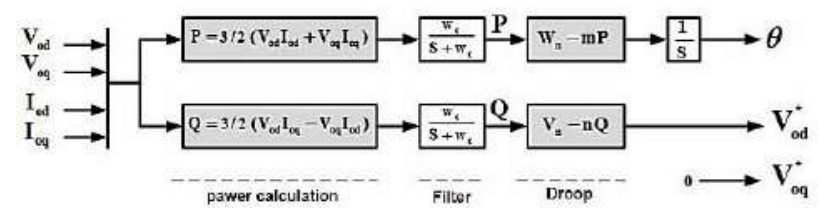

Fig. 4. Reactive power controller in the island fashion

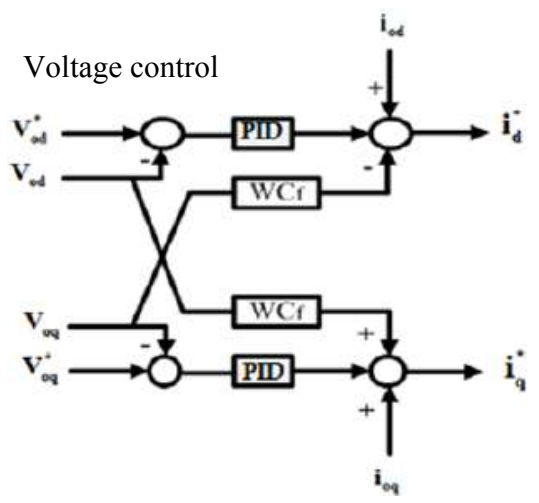

Fig. 5. Voltage controller in the island fashion

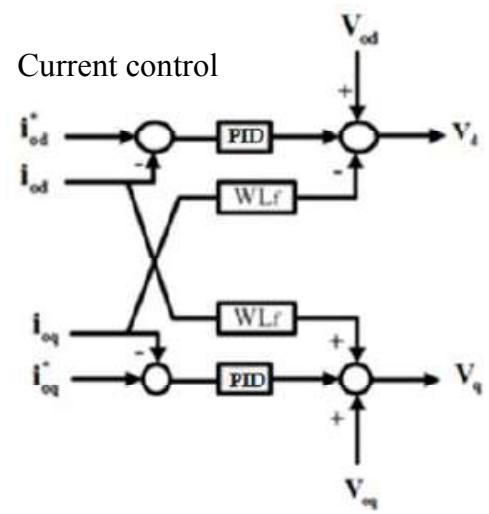

Fig. 6. Current controller in the island fashion

Optimization method for PID controller parameters with adaptive control. The parameters considered in the optimization of the coefficients are IIK, PIK, IVK, and PVK. The optimization goal is to minimize current and voltage errors according to the Fig. 7.

The considered Micro-grid parameters are simulated in MATLAB software and the results of their optimization by adoptive control method are presented in the following Tables 2, 3 .

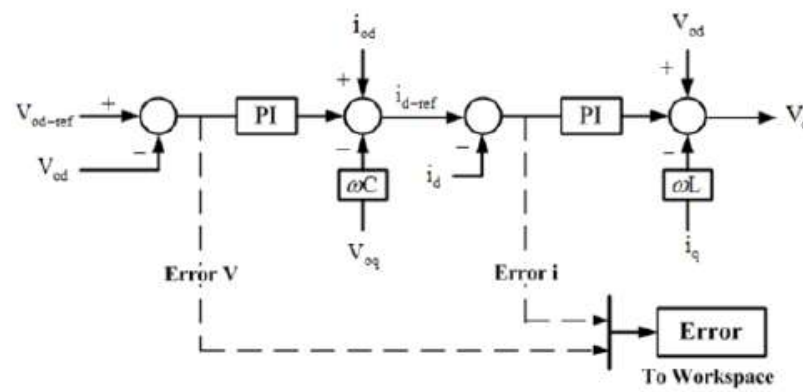

Fig. 7. Optimization of controller parameters by minimizing voltage and current errors

Table 2

Network parameters studied

\begin{tabular}{|c|c|c|}
\hline \multicolumn{1}{|c|}{ Parameter } & Value \\
\hline \multirow{4}{*}{$\mathrm{DG}_{1}, \mathrm{DG}_{2}$} & Source voltage $V_{\mathrm{DC}}$ & $580 \mathrm{~V}$ \\
\cline { 2 - 3 } & Inductance filter inverter $\left(L_{\mathrm{f}}\right)$ & $1 \mathrm{mH}$ \\
\cline { 2 - 3 } & Capricanticism filter inverter $\left(C_{\mathrm{f}}\right)$ & $50 \mu \mathrm{F}$ \\
\cline { 2 - 3 } & Frequency switching inverter $\left(f_{\mathrm{s}}\right)$ & $8 \mathrm{kHz}$ \\
\cline { 2 - 3 } & $m$ & $6.25 \cdot 10^{-5}$ \\
\cline { 2 - 3 } & $n$ & $1.8 \cdot 10^{-3}$ \\
\cline { 2 - 3 } & $f_{\mathrm{n}}$ & $50 \mathrm{~Hz}$ \\
\hline$V_{\mathrm{n}}$ & $220 \sqrt{2}$ \\
\hline \multicolumn{2}{|c|}{$Z_{2}$} & $0.424 \mathrm{j} \Omega$ \\
\hline \multicolumn{2}{|c|}{ Power } & $6 \mathrm{~kW}$ \\
\hline \multicolumn{2}{|c|}{ Voltage effective line } & $220 \sqrt{3}$ \\
\hline
\end{tabular}

Table 2

Results obtained from optimization

\begin{tabular}{|c|c|c|c|}
\hline & $K_{P}$ & $K_{I}$ & $K_{D}$ \\
\hline Normal PID control & 0.13034 & 10.418 & 0.63969 \\
\hline Adaptive PID control & 0.32987 & 39.962 & 1.0926 \\
\hline
\end{tabular}

To check the performance of the controller, the load at the instant of $t=0.6 \mathrm{~s}$ is changed from $6 \mathrm{~kW}$ to $10 \mathrm{~kW}$. The following is the simulation's output with parameters optimized by comparative control.

According to the obtained forms:

- power is divided between units in proper mode;

- frequency drops are within permissible range.

Simulation outputs are desirable. Although there are overshoot in outputs, but its value is ignorable. Also, the output speed is desired. Simulation outputs with parameters optimized by adoptive control method are also given below. With regard to the output figures with optimized parameters, the following results are achievable:

- power is divided between units;

- frequency drops are in the allowed range.

Simulation outputs are desirable in terms of speed and overshoot and there is no overshoot and undershoot in the responses (Fig. 8).

In this Fig. 8 distributed generation (DG) is an approach that employs small-scale technologies to produce electricity close to the end users of power. DG technologies often consist of modular (and sometimes renewable-energy) generators, and they offer a number of potential benefits.

As a result, it is notable that the optimization of the adoptive control is done correctly and the system has optimal response with these optimal parameters. 


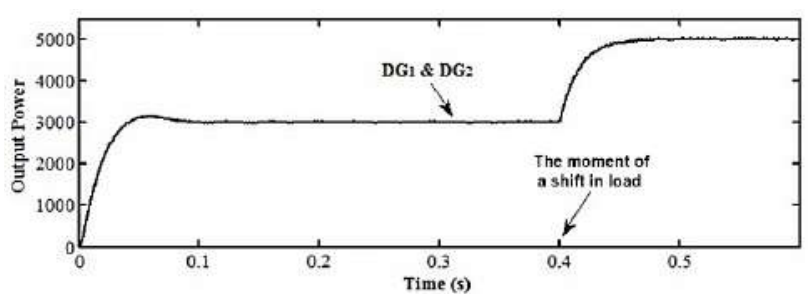

Fig. 8. Output power of DGs with parameters optimized by adaptive control

Stability analysis method for determining the function of converting voltage and current controllers. Block current controller diagram in island state shown in Fig. 9, where $V_{0}$ is the disturbance input.

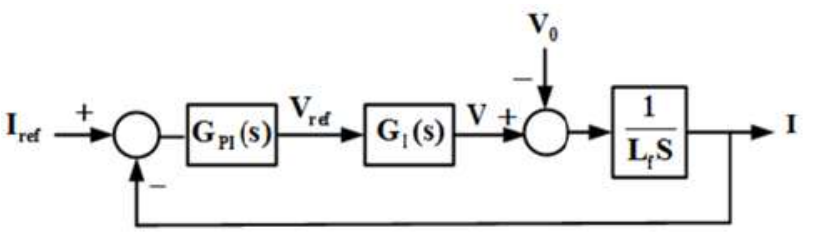

Fig. 9. Block current controller diagram in island state

The inverter conversion function is $\mathrm{G}_{\mathrm{I}}(\mathrm{S})=1$ and $\mathrm{G}_{\mathrm{PI}}(\mathrm{S})$ is PID controller conversion function, expressed as

$$
G_{P I}(S)=K_{P I D}+\frac{K_{I I}}{S} .
$$

Block diagram of voltage controller in island state shown in Fig. 10, where $I_{0}$ is the disturbance input.

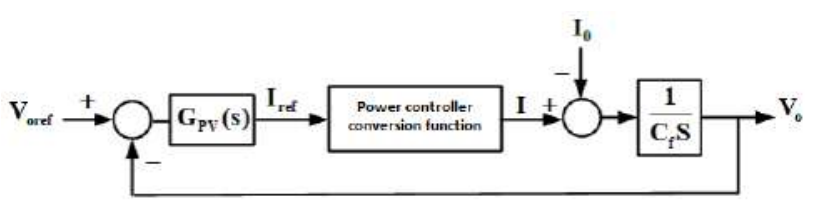

Fig.10. Block Diagram of Voltage Controller in Island State follows

$\mathrm{G}_{\mathrm{PV}}(\mathrm{S})$ is the PID controller conversion function, as

$$
G_{P V}(S)=K_{P V}+\frac{K_{I V}}{S} .
$$

In order to obtain the voltage controller conversion function, firstly obtain the current controller conversion function and then, the conversion function obtained will be considered in the voltage controller. The stability of the controller can be checked upon obtaining the open loop and closed loop function and having parameters. In order to analyze the stability of the optimal comparator control, first, the stability of the current controller and then the stability of the voltage controller must be checked. These analyses are performed according to the parameters optimized by comparative control.

The current controller conversion function is

$$
T_{I-\text { Adaptive }}(S)=\frac{1.3123 \cdot S+309.08}{0.5 \cdot 10^{-3} \cdot S^{2}+1.3123 \cdot S+309.08} \text {. }
$$

The graph of these conversion functions is shown in the Fig. 11, 12. Considering the Figure it is founded that the margin of interest and the margin of the controller phase are positive; therefore, the system is stable.

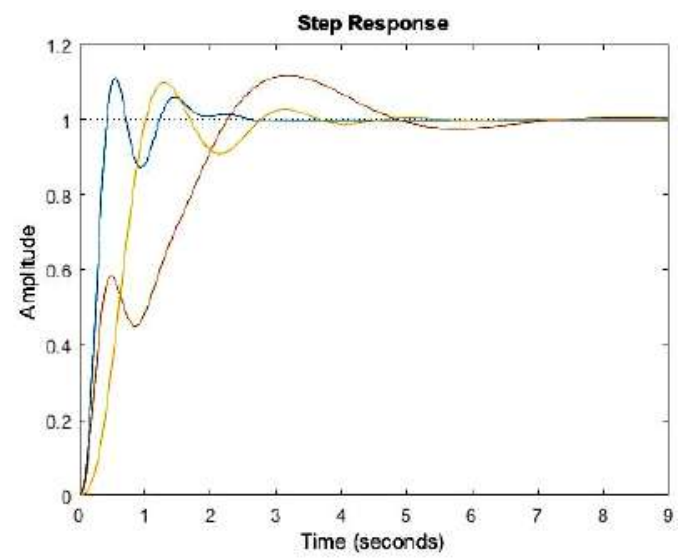

Fig. 11. Voltage controller stage response in island state with parameters optimized by adaptive control

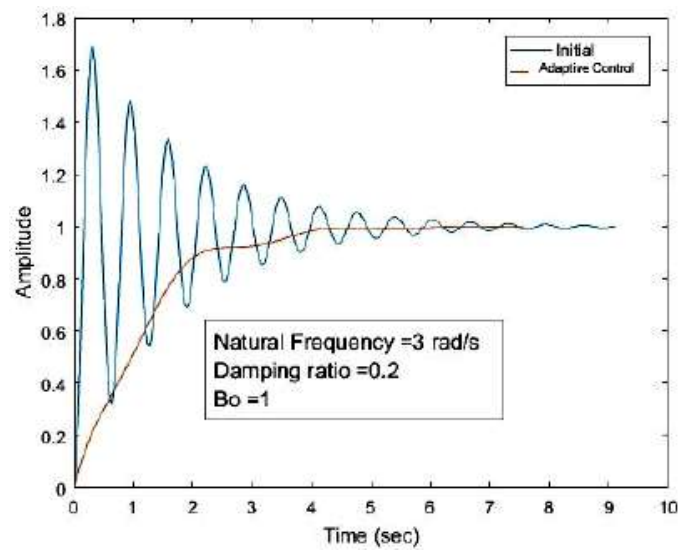

Fig. 12. Controller stage response in island state with parameters optimized by adaptive control

Conclusion. The adoptive control method was used to select the optimal PID controller parameters in Microgrid. The sample grid and the adoptive control used for finding the most optimal response were implemented in MATLAB software. The simulation results show the correct control of the reactive power between the Microgrids distributed generation sources. These simulation results also indicate that the optimization of the parameters is done correctly and the system responses are desirable. These responses were evaluated in terms of the speed and error of the steady state.

Sustainability analysis was performed with optimized parameters and the stability of the systems with bad graphs and their performance and speed were investigated with step responses. The performance of these systems was also investigated against step type turbulence. The results of this thesis once again indicate the requirement of proper selection of correct controller coefficients, because the lack of proper selection may lead to undesirable and oscillatory responses of the system.

\section{REFERENCES}

1. Elkhatib M.E., El-Shatshat R., Salama M.M.A. Novel Coordinated Voltage Control for Smart Distribution Networks with DG. IEEE Transactions on Smart Grid, 2011, vol.2, no.4, pp. 598-605. doi: 10.1109/TSG.2011.2162083.

2. Pepermans G., Driesen J., Haeseldonckx G., Belmans R., D'haeseleer W. Distributed generation: definition, benefits and issues. Energy Policy, 2005, vol.33, no.6, pp. 787-798. doi: 10.1016/j.enpol.2003.10.004. 
3. Mandis A.C., Manoloiu A., StefanaNeagoe A.G., Leonida T., Neagoe A.C. Impact of distributed generation on steady state of electrical networks. Proceedings of ISFEE '2014 International Symposium on Fundamentals of Electrical Engineering. doi: 10.1109/ISFEE.2014.7050605.

4. Rezaei N., Haghifam M-R. Protection scheme for a distribution system with distributed generation using neural networks. International Journal of Electrical Power \& Energy Systems, 2008, vol.30, no.4, pp. 235-241. doi: 10.1016/j.ijepes.2007.07.006.

5. Poornazaryan B., Karimyan P., Gharehpetian G.B., Abedi M. Optimal allocation and sizing of DG units considering voltage stability, losses and load variations. International Journal of Electrical Power \& Energy Systems, 2016, vol.79, pp. 42-52. doi: 10.1016/j.ijepes.2015.12.034.

6. Sheng W., Meng X., Zhao S., Song X. Maximum penetration level of distributed generation in consideration of voltage fluctuations based on multi-resolution model. IET Generation, Transmission \& Distribution, 2015, vol.9, no.3, pp. 241-248. doi: 10.1049/iet-gtd.2013.0883.

7. Pandi V.R., Zeineldin H.H., Xiao W. Determining Optimal Location and Size of Distributed Generation Resources Considering Harmonic and Protection Coordination Limits. IEEE Transactions on Power Systems, 2013, vol.28, no.2, pp. 1245-1254. doi: 10.1109/TPWRS.2012.2209687.

8. Bevrani H., Ghosh A., Ledwich G. Renewable energy sources and frequency regulation: survey and new perspectives. IET Renewable Power Generation, 2010, vol.4, no.5, pp. 438457. doi: 10.1049/iet-rpg.2009.0049.

9. Shiva C.K., Mukherjee V. Automatic generation control of interconnected power system for robust decentralized random load disturbances using a novel quasioppositional harmony search algorithm. International Journal of Electrical Power \& Energy Systems, 2015, vol.73, pp. 991-1001. doi: 10.1016/j.ijepes.2015.06.016.

10. Rerkpreedapong D., Hasanovic A., Feliachi A. Robust load frequency control using genetic algorithms and linear matrix inequalities. IEEE Transactions on Power Systems, 2003, vol.18, no.2, pp. 855-861. doi: 10.1109/TPWRS.2003.811005.

11. Esmaeli A. Stability analysis and control of microgrids by sliding mode control. International Journal of Electrical Power \& Energy Systems, 2016. vol.78, pp. 22-28. doi: 10.1016/j.ijepes.2015.11.068.
12. Miveh M.R., Rahmat M.F., Ghadimi A.A., Mustafa M.W. Control techniques for three-phase four-leg voltage source inverters in autonomous Micro-grids: A review. Renewable and Sustainable Energy Reviews, 2016, vol.54, pp. 1592-1610. doi: 10.1016/j.rser.2015.10.079.

13. Khalghani M.R., Khooban M.H., Mahboubi-Moghaddam E., Vafamand V., Goodarzi M. A self-tuning load frequency control strategy for Micro-grids: Human brain emotional learning. International Journal of Electrical Power \& Energy Systems, 2016, vol.75, pp. 311-319. doi: 10.1016/j.ijepes.2015.08.026.

14. Ghanbarian M.M., Nayeripour M., Rajaei A., Mansouri M.M. Design and implementation of a new modified sliding mode controller for grid connected inverter to controlling the voltage and frequency. ISA Transactions, 2016, vol.61, pp. 179187. doi: 10.1016/j.isatra.2015.11.023.

15. Mahmoud M.S., Alyazidi N.M., Abouheaf M.I. Adaptive intelligent techniques for Micro-grid control systems: A survey. International Journal of Electrical Power \& Energy Systems, 2017, vol.90, pp. 292-305. doi: 10.1016/j.ijepes.2017.02.008.

16. Shariatzadeh F., Kumar N., Srivastava A.K. Optimal Control Algorithms for Reconfiguration of Shipboard Microgrid Distribution System Using Intelligent Techniques. IEEE Transactions on Industry Applications, 2017, vol.53, no.1, pp. 474-482. doi: 10.1109/TIA.2016.2601558.

17. Sedighizadeha M., Esmaili M., Eisapour-Moarref A. Voltage and frequency regulation in autonomous Micro-grids using Hybrid Big Bang-Big Crunch algorithm. Applied Soft Computing, 2017, vol.52, pp. 176-189. doi: 10.1016/j.asoc.2016.12.031.

Received 07.05.2019

Amin Moghayadniya ${ }^{1}$, Candidate of Power Engineering, M.Sc. Student,

S. Ehsan Razavi ${ }^{1}$, Doctor of Control Engineering, Assistant

Professor,

${ }^{1}$ Department of Electrical Engineering,

Mashhad Branch, Islamic Azad University,

Ostad Yusofi Str., Emamieh Boulevard, GhasemAbad,

Mashhad, Iran.

e-mail: ehsanrazavi@mshdiau.ac.ir,

e_razavi_control@yahoo.com 


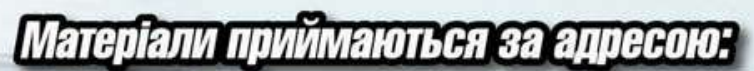

पa.p

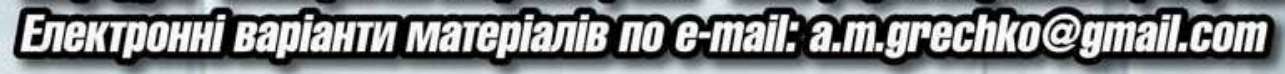

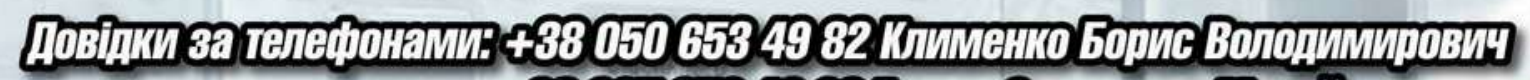

43803783594396 [1
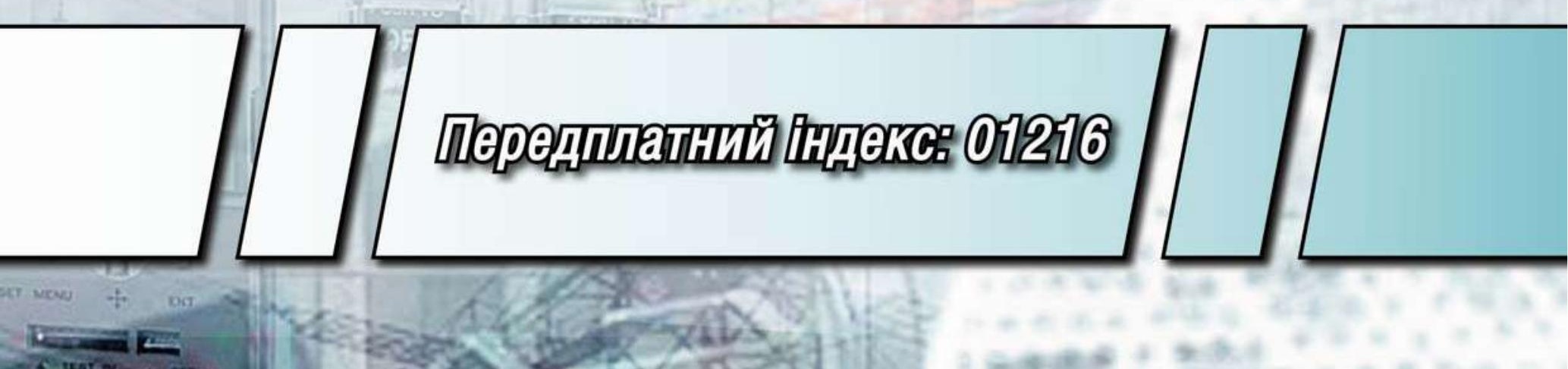

$\frac{10}{008}$

imes:

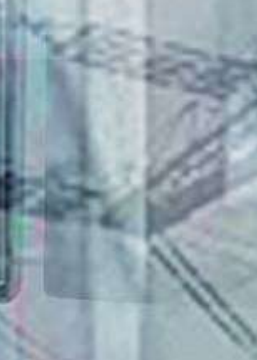

LOCK IN OFF

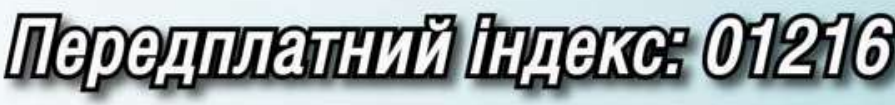

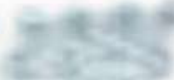

